\title{
PETTIT E ROUSSEAU: SOBRE CONTESTABILIDADE
}

Fernanda Diab ${ }^{1}$

\section{Resumen:}

Pettit distingue dos tradiciones republicanas, una de origen ítalo-atlántico y otra franco-alemana. Mientras él se identifica con la primera, el pensamiento de Rousseau es uno de los pilares teóricos de la segunda. Ambas coinciden en la defensa de la libertad como no dominación pero difieren fundamentalmente en su concepción de ciudadanía y representación. Pettit sostiene que Rousseau enfrenta una situación dilemática entre la defensa de la libertad como no-dominación y el rechazo de la representación. Para que el Estado no se convierta él mismo en fuente de dominación es necesario generar vías de contestación para la ciudadanía lo cual sólo es posible - según Pettit - en un régimen de constitución mixta. Al rechazar la representación Rousseau no daría cuenta de estos canales y negaría la posibilidad de revisar y cambiar el curso de las leyes y las políticas que no persigan el bien común. En este artículo sostengo que la defensa de Pettit sobre la existencia de una situación dilemática en la teoría de Rousseau entre la defensa de la no dominación y el rechazo a la representación se realiza asumiendo una versión densa de la voluntad general, y que a partir de una caracterización alternativa de la misma, como - por ejemplo - la propuesta por John Rawls, es posible fundamentar que en Rousseau la contestación del poder público sí está justificada.

Palabras clave: Pettit Philip. Rousseau. Contestación. Voluntad general. Libertad como no dominación.

\section{PETTIT AND ROUSSEAU: ABOUT CONTESTABILITY}

\begin{abstract}
:
Pettit distinguishes two republican traditions one of Italian-Atlantic origin and another Franco-German one. While he identifies with the first, the thought of Rousseau is one of the theoretical pillars of the second. Both agree in the defense of freedom as non-domination but differ fundamentally in their conception of citizenship and representation. Pettit argues that Rousseau faces a dilemma between the defense of freedom as non-domination and the rejection of representation. In order for the State not to become a source of domination, it is necessary to generate means of contestation for citizenship, which is only possible - according to Pettit - in a regime of mixed constitution. By rejecting the representation Rousseau would not account for these channels and would deny the possibility of revising and changing the course of laws and policies that do not pursue the common good. In this article I argue that Pettit's defense of the existence of a dilemmatic situation in Rousseau's theory between the defense of nondomination and the rejection of representation is done by assuming a dense version of the general will, and that from an alternative characterization of it, such as - for example - the one proposed by John Rawls, it is possible to base that in Rousseau the disputation of the public power is justified.
\end{abstract}

Keywords: Pettit Philip. Rousseau. Contestation. General will. Freedom as non-domination.

1 Universidad de la República (Uruguay) - Facultad de Humanidades y Ciencias de la Educación. Docente (Grado 2) del Departamento de Filosofía de la Práctica del Instituto de Filosofía. Magíster en Ciencias Humanas - Opción Filosofía Contemporánea (2017) por la Facultad FHCE-UDELAR. Email: fernanda.diab@gmail.com. 


\section{Introducción}

El filósofo irlandés Philip Pettit mantiene a través de sus trabajos una relación ambivalente con el pensamiento de Jean Jacques Rousseau. El aspecto positivo por el cual el filósofo se siente emparentado con el ginebrino es la defensa de la no dominación como modelo de libertad política. El valor de no estar sometido a la voluntad de otro constituye uno de los pilares fundamentales del republicanismo y en este sentido Pettit concibe su modelo teórico como perfectamente conciliable con el de Rousseau e igualmente republicano. Sin embargo en términos de diseño institucional, dado el rechazo de Rousseau a un modelo de constitución mixta, Pettit estima que se produce un distanciamiento entre ambos modelos por la afectación que ello produce en la dimensión contestataria de la democracia republicana, aspecto medular de su teoría política. En este sentido Pettit se distancia de la tradición republicana con la que identifica a Rousseau y comprende su teoría como heredera de otra línea republicana: la ítalo-atlántica.

A la vez que identifica a Rousseau con otra tradición entiende que éste enfrenta una situación dilemática entre la defensa de la libertad como no-dominación y el rechazo de la representación. Para evitar que el Estado se convierta él mismo en fuente de dominación es necesario generar vías de contestación para la ciudadanía y esto sólo es posible - según Pettit - en un régimen de constitución mixta. Al rechazar la representación Rousseau no daría cuenta de estos canales y rechazaría la posibilidad de revisar y cambiar el curso de las leyes y las políticas que no persigan el bien común. En este artículo sostengo que la justificación de Pettit sobre la existencia de una situación dilemática en Rousseau entre la defensa de la no dominación y el rechazo a la representación se realiza asumiendo una perspectiva organicista de la voluntad general, y que es posible fundamentar desde otras perspectivas desde las que se analizan los rasgos de la voluntad general - por ejemplo la ofrecida por John Rawls - que la contestación del poder público en Rousseau sí está justificada.

En una primera parte del trabajo se planteará la distinción que Pettit desarrolla de dos tradiciones republicanas a partir de la cual distingue su modelo político del republicanismo rousseauniano, reconociendo igualmente que existe una fuerte coincidencia en la defensa que ambos realizan de la libertad política entendida

\begin{tabular}{|l|l|l|l|l|}
\hline Q Rovista Dialactus & Ano 8 & n. 15 & Agosto-Dezembro 2019 & p. $72-87$ \\
\hline
\end{tabular}


como no dominación. A continuación se abordará el dilema que Pettit identifica entre la defensa de este modelo de libertad política y la negativa de Rousseau frente a un modelo de constitución mixta así como sus consecuencias con respecto a la posibilidad o no de contestación ciudadana. Finalmente se analizará la versión densa de la voluntad general, enfoque desde el cual ésta es comprendida como una unidad homogénea e indivisible, y que, sostengo, es la noción que Pettit asume para argumentar que el modelo teórico de Rousseau niega la contestación, aspecto que resulta ser el más distintivo con respecto a la tradición republicana ítalo-atlántica. A partir de allí pretendo fundamentar que desde una caracterización alternativa de la voluntad general defendible a partir del propio Rousseau, se justifica en su teoría política la posibilidad de la disputación y la reformulación de las decisiones públicas, sin por ello admitir que se esté atentando contra el poder soberano.

\section{Dos republicanismos}

Pettit identifica dos vertientes teóricas dentro del republicanismo. Una de ellas ligada al pensamiento de Jean Jacques Rousseau y a Immanuel Kant, antes a la Atenas de Pericles y contemporáneamente a filósofos como Hannah Arendt y Michael Sandel. La misma se caracteriza por concebir la vida pública como un aspecto constitutivo de la esencia humana. Es en la participación como ciudadanos que se logra el florecimiento y se alcanza la auténtica libertad. Los principales exponentes del neorepublicanismo en teoría política, Philip Pettit y Quentin Skinner, en cambio identifican sus modelos teóricos, en particular la noción de libertad política y el correspondiente diseño institucional para su resguardo, con la tradición republicana ítalo-atlántica heredera de la República romana y asociada a nombres como Cicerón, Maquiavelo - de los Discursos -, más adelante con James Harrington así como a referentes teóricos de la Commonwealth inglesa y norteamericana del siglo XVIII, y presente también en las discusiones entre federalistas y anti-federalistas. (Pettit, 1999, p.22-23). Esta vertiente concibe la actividad pública como un medio, es decir como un instrumento, para alcanzar y salvaguardar la libertad y no como un aspecto sustantivo de la misma. De esta tradición recuperan principalmente la distinción entre amo (sui iuris) y esclavo (alienis iuris) para la caracterización de la libertad política.

\begin{tabular}{|l|l|l|l|l|}
\hline Q Revista Dialectus & Ano 8 & n. 15 & Agosto-Dezembro 2019 & p. 72-87 \\
\hline
\end{tabular}


El modelo político de Pettit se centra en el valor normativo de la no dominación, entendiendo que este constituye el bien último a ser resguardado. ${ }^{2} \mathrm{El}$ estado de dominación es el mayor de los peligros que se debe evitar a través del orden social y político, considerando que lo opuesto al hombre libre es el siervo o el esclavo. Es decir que el concepto republicano de libertad se construye por contraposición al de servidumbre o esclavitud. El siervo no vive cómo quiere sino que depende de la voluntad del amo, es alienis iuris, que significa que se encuentra bajo jurisdicción ajena. La dominación se identifica con el control enajenante que otros ejercen actual o potencialmente sobre alguien. Es decir que la situación de dominación no necesita de una interferencia permanente, basta con la latente capacidad para interferir de una parte sobre la otra, distinguiéndose en este sentido de la noción liberal de libertad como no interferencia. Si por benevolencia o negligencia el esclavo no se viera interferido, no significa que ha superado la situación de servidumbre. El amo puede interferir si quiere y si no quiere o las circunstancias así lo indican, puede no hacerlo. Es por este aspecto que se afirma que la dominación para el republicanismo es modal. (De Francisco, 2007, p.125).

El poder que ejerce el amo es arbitrario porque depende exclusivamente de su voluntad y no necesita justificación alguna de sus actos u omisiones. El hombre libre en cambio es sui iuris, vive como quiere sin la imposición ajena de un modo de vida particular. Sin embargo tal libertad no se concibe en la tradición republicana independientemente de la calidad de ciudadano. La libertas y la civitas para un romano expresan lo mismo aunque la primera pone el énfasis en la dimensión individual la segunda refiere al estatus del individuo como ciudadano, como parte de la comunidad. ${ }^{3}$ Estos son los aspectos centrales que el republicanismo contemporáneo ha recuperado.

Sin embargo la anterior no es la única vertiente republicana con legado filosófico. Pettit identifica y distingue de la anterior a la tradición republicana francoalemana fundada en el pensamiento de Jean Jacques Rousseau e Immanuel Kant, a los efectos del presente trabajo sólo se tomará en consideración el pensamiento del ginebrino. Reconoce en ellos la defensa del ideal de no dominación entendido como la

2 Algunos autores han cuestionados esta posición: por ejemplo, Pinzani (2007), cuestiona que el neo republicanismo se centre en la noción de libertad ya que considera que el republicanismo se centra en el valor de las instituciones políticas.

3 Wirszubski, (1968, p. 3-4), citado en Braithwaite \& Pettit, (2015, p.78).

\begin{tabular}{|c|c|c|c|c|}
\hline Govista Dialectus & Ano 8 & n. 15 & Agosto - Dezembro 2019 & p. $72-87$ \\
\hline
\end{tabular}


no sujeción a la voluntad arbitraria de alguien más, aunque también se les debe la inauguración de una línea de pensamiento republicano basada en una nueva concepción tanto de ciudadanía como de Estado. Por la gran influencia de esta nueva vertiente, llegó a convertirse en la imagen dominante del republicanismo (Pettit, 2013). En su libro Republicanismo, Pettit atribuye a Rousseau el haber dado lugar a esta nueva vertiente republicana a la que denomina "populista". Ese "giro populista" significó la introducción del ideal de "autodominio democrático", convirtiéndose esta concepción en la alternativa más importante al ideal liberal de la no interferencia. En este enfrentamiento el modelo republicano franco-alemán se convirtió en el principal blanco de las críticas liberales y tornó a la vez invisible a la anterior tradición republicana.

\begin{abstract}
Por republicanos y atractivos que puedan resultar sus puntos de vista en otros respectos, Rousseau es probablemente responsable de haber dado pábulo a este enfoque populista. El giro populista significó un nuevo desarrollo, y cobró forma definida sólo cuando el ideal del autodominio democrático se convirtió en la principal alternativa - o al menos, en la principal alternativa entre las distintas nociones de libertad - al ideal negativo de la nointerferencia. Pensar que la tradición republicana es populista, como - huelga decirlo - han hechos tantos, monta tanto como afirmar la misma dicotomía que ha tomado invisible al ideal republicano. (PETTIT, 1999, 47).
\end{abstract}

La herencia ítalo-atlántica se sostiene en los siguientes tres pilares: en la igual libertad de los ciudadanos, entendida como no dominación; en las constricciones constitucionales es decir los mecanismos constitucionales tendientes a evitar el imperium estatal como la división de poderes o la rotación de los magistrados; y en la contestación pública en el entendido de que es lo único que impide la existencia de un

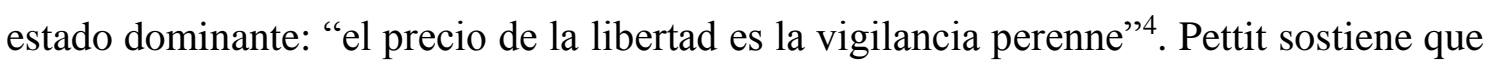
ambas tradiciones republicanas comparten la defensa de la libertad como no dominación entendida como independencia respecto a la voluntad de otros pero difieren en los dos restantes aspectos. (Pettit, 2013, p.176).

Rousseau en su obra mantiene una defensa de la libertad entendida como no sujeción y a la que todo ciudadano debe aspirar, vía las garantías que le ofrece el Estado, lo cual - según Pettit - "es una clara variante de la libertad como nodominación" (Pettit, 2013, p.176-177). Pero Rousseau se encuentra de camino entre dos

4 Hace referencia a un famoso epigrama acuñado en 1790 por el juez y político irlandés radical John Curran. (Pettit, 1999, p.23).

\begin{tabular}{|c|c|c|c|c|}
\hline Revista Didectus & Ano 8 & n. 15 & Agosto - Dezembro 2019 & p. $72-87$ \\
\hline
\end{tabular}


tradiciones - sostiene Pettit - ya que por un lado comparte con la tradición neo-romana la conexión entre ser libre y no estar sujeto a la voluntad arbitraria de un amo u otros individuos capaces de interferir en nuestras vidas; mientras que por otro lo halla vinculado a una tradición de origen medieval de donde toma la idea de la identidad pública como una corporación, una visión organicista de la soberanía popular. ${ }^{5}$ Sin embargo la mayor influencia la recibió de Hobbes y Bodin de quienes heredó la noción de soberanía entendida como un poder absoluto e indivisible. De acuerdo con su perspectiva cualquier forma de división supone una fuente de conflicto y por tanto de debilidad. Previo a la incorporación al Estado los individuos solo constituyen voces disonantes y al incorporarse al cuerpo político se convierten en un agente, se conforma una voluntad que se transforma en una voz autorizada. Es el portavoz quien encarga la soberanía y por ello tiene que tener unidad, ser absoluto e indivisible. (Pettit, 2013, p.183). Este aspecto conduce directamente a una fuerte crítica de la constitución mixta ${ }^{6}$, uno de los mecanismos institucionales más importantes del republicanismo en la primera vertiente, ya que la misma autorizaría la coexistencia de diferentes portavoces, debilitando la estabilidad del Estado.

Si bien en Rousseau existe una recomendación de una especie de gobierno mixto (CS, 2008, III, cap.7, p.130), Pettit sostiene que esto es distinto a una constitución mixta. A diferencia de la constitución mixta, el gobierno mixto seguiría siendo consistente con la unidad soberana. (Pettit, 2016, p.16). La negativa de Rousseau a una constitución mixta se basa en su cuestionamiento a los modelos que dividen la soberanía entre cuerpos y por ello desconocen la presencia de una única voluntad en el origen de la ley. (Pettit, 2013, p.184-185). En su lugar propone que la única fuente legítima de la ley es la voluntad de la mayoría, es el pueblo quien elabora y otorga legitimidad a las leyes, siendo así el único soberano. Al pertenecer al cuerpo soberano cada individuo alcanza el mayor grado de libertad porque no queda sometido a la

5 Berges Sandrine. Interview with Professor Philip Pettit. En: Étique et économique/Ehics and Economics, 3 (2), 2006, p.1.

6 Entiendo que Pettit asume sin mayor discusión la noción de constitución mixta concebida como el mecanismo institucional de división de poderes. Sin embargo la noción de constitución mixta remite a una noción pre-moderna que parte del reconocimiento y asunción de los diferentes estratos sociales los cuales deben estar todos representados en el gobierno: la monarquía, la nobleza, el pueblo. Sobre el tema ver por ejemplo: Rivera García, Antonio, (2011, p. 171-197).

\begin{tabular}{|l|c|c|c|c|}
\hline Govista Dialectus & Ano 8 & n. 15 & Agosto-Dezembro 2019 & p. 72-87 \\
\hline
\end{tabular}


voluntad de ninguno, lo cual se expresa en el célebre pasaje rousseauniano: "Cada uno dándose a todos no se da a ninguno" (CS, 2008, I, cap.6, p.55).

Pettit sostiene que es en este punto en el cual Rousseau se distancia definitivamente de la tradición republicana ítalo-atlántica ya que tal estatus del individuo con respecto a la voluntad general impide la representatividad y la división de poderes, clausurando de este modo la posibilidad de contestación.

\begin{abstract}
Mientras Rousseau concibe un ideal bajo el cual las personas son independientes uno de otro como personas privadas, en línea con la concepción de libertad recibida, piensa que su mutua independencia es sostenible sólo al costo de una forma de sumisión a la persona pública específicamente, a la voluntad general o colectiva de la persona pública - que estaría completamente en desacuerdo con los sentimientos Ítalo-Atlánticos. (PETTIT, 2013, 186) ${ }^{7}$.
\end{abstract}

Entonces la negación de una constitución mixta no solamente conlleva - según Pettit - una afectación de la libertad como no dominación de la persona frente al poder público (lo que denomina imperium) sino que introduce una nueva concepción de ciudadanía no republicana (Pettit, 2013, p.193). La ciudadanía es legisladora y soberana, por lo cual la contestación de sus decisiones carecería de sentido, cualquier intento de disputación supondría que el ciudadano reclamara ante sí mismo. Al no existir autoridad entre la voluntad general y la particular, la contestación sería inconducente. Cualquier intento de contestación afectaría la unidad de la voluntad soberana ya que el individuo estaría actuando desde su voluntad particular y dado que "la voluntad es general o no lo es" (CS, 2008, II, cap.2, p.69) de hecho el pacto se disolvería. Cuando esto ocurre el pacto se vuelve "tiránico e inútil", en consecuencia para garantizar la unidad e igualdad que provee la asociación es necesario aceptar que "ningún asociado tiene nada que reclamar" (CS, 2008, I, cap.6, p.55).

Los ciudadanos no son grandes vigilantes del gobierno, alerta frente a cualquier posible error y prontos a desafiar y contestar a las autoridades legislativa, ejecutiva y judicial. Los ciudadanos de Rousseau son hacedores de leyes, no chequeadores de leyes, generadores de leyes no testeadores de leyes. Ellos sirven en la producción de decisiones públicas, no en controlar la calidad de esas decisiones. (Pettit, 2013, p.193-194).

$7 \quad$ La traducción es propia.

\begin{tabular}{|c|c|c|c|c|}
\hline Revista Dinlectus & Ano 8 & n. 15 & Agosto - Dezembro 2019 & p. $72-87$ \\
\hline
\end{tabular}




\section{El dilema de Rousseau}

Sobre lo anterior Pettit justifica que Rousseau se aleja de la tradición republicana por sostener "un ideal de soberanía popular en lugar de la constitución mixta y un ideal de ciudadanía participante en la creación de leyes en lugar de una ciudadanía contestataria" (Pettit, 2013, p.195). En este contexto no podría garantizarse la libertad del ciudadano con respecto a la dominación estatal, estaría libre del dominium (libertad con respecto a los otros individuos o grupos faccionales) pero no frente al imperium (el poder del cuerpo político), ya que para Pettit esto no es posible si no queda garantizada la disputación de las decisiones públicas. Sostiene que Rousseau enfrenta un dilema surgido a partir de la problemática que supone responder a la pregunta inicial del Contrato sobre la posibilidad de establecer un pacto sin perder por ello nuestra libertad. Una vez planteadas las respuestas frente a los dos problemas de la libertad: cómo sujetarnos legítimamente a un cuerpo político para garantizar la igual libertad y cómo evitar que la asamblea se desvíe de la voluntad general al verse afectada por intereses parciales, cabe preguntarse - dice Pettit - si "las personas tienen derecho a rechazar la subordinación a la asamblea soberana" cuando se producen desviaciones con respecto al objetivo del bien común. Rousseau podría responder sí o no a esta pregunta, y Pettit sostiene que en ningún caso ofrecería una respuesta satisfactoria" (Pettit, 2016, p.28).

El primer argumento expuesto por Pettit se basa en el problema de la estabilidad. La respuesta afirmativa a la pregunta planteada convertiría la meta de la estabilidad estatal en algo inalcanzable debido a la permanente posibilidad de romper el pacto.

De acuerdo con el enfoque sugerido, los ciudadanos tendrían derecho a retirarse de su comunidad, rechazando la legitimidad de sus leyes, tan pronto como fueran persuadidos, correcta o incorrectamente, de que la asamblea está atendiendo los intereses de una facción en lugar del interés de los miembros. Esta sería una receta para el caos, ya que es una posibilidad permanente en cualquier sociedad, por perfecto que sea el régimen, que la gente sea persuadida de que la asamblea ha sido tomada por el interés de facciones. (PETTIT, 2016, p.29). ${ }^{8}$

8 La traducción es propia.

\begin{tabular}{|c|c|c|c|c|}
\hline Revista Dinlectus & Ano 8 & n. 15 & Agosto - Dezembro 2019 & p. $72-87$ \\
\hline
\end{tabular}


El segundo argumento refiere la coerción ilegítima del Estado. Si Rousseau respondiera negativamente a la pregunta sobre la posibilidad de contestar el poder estatal cuando se percibe que el mismo no está respondiendo al interés común, entonces su modelo teórico justificaría un Estado dominante según lo entiende Pettit. En tanto la respuesta afirmativa habilitaría una especie de anarquismo, esta respuesta negativa haría lo mismo con un modelo despótico (Pettit, 2016, p.29).

Pettit interpreta que no es plausible encontrar una defensa de la contestación en Rousseau ya que las situaciones de subyugación a las que el ginebrino se refiere, y en las cuales sería posible alguna forma de disputa, no se vinculan con una asamblea dividida en intereses faccionales sino a un estado de dispersión de los individuos previo al pacto (Pettit, 2016, p. 30). En contraste entiende que el ginebrino tiene "una buena razón para aceptar la segunda respuesta" y es que a pesar de que un Estado puede degenerar en un despotismo en donde "ya no hay libertad" los ciudadanos de todos modos no podrían cuestionar al soberano. Pettit se apoya en el pasaje del Contrato en el cual Rousseau afirma que cualquier enajenación que el individuo sufra en virtud del pacto social será potestad sólo del juicio soberano (CS, 2008, II, cap.4, p.73). Luego el potencial disputativo de los ciudadanos queda debilitado en su vínculo con el gobierno y este aspecto es lo que definitivamente lo distancia de la tradición republicana.

\begin{abstract}
Entiendo que según la antigua tradición que Rousseau buscó revisar, un régimen contará como legítimo en la medida en que sus decisiones estén sujetas al control igualitario de la ciudadanía en medida suficiente para permitirles pasar el eyeball test en relación con el gobierno. En esta forma de pensar, no miramos para ver si la sociedad se basa en un consentimiento pasado o continuo para determinar si es legítimo; buscamos si está controlada por la ciudadanía en medida suficiente y con suficiente igualdad, para que cada uno pueda ver a las autoridades ante los ojos sin motivo de temor o deferencia (PETTIT, 2016, p.33).
\end{abstract}

Para Pettit el republicanismo puede ser perfectamente compatible con algún tipo de faccionalismo, siendo el trasfondo de tal convicción una asunción normativa del pluralismo social aspecto esencial de las sociedades modernas. Existen intereses sectoriales vinculados a la coexistencia de diversas y múltiples concepciones de vida. Cuando las decisiones públicas se toman en virtud de esos intereses parciales más que en base a intereses comunes, serán legítimas si han sido tomadas bajo términos constitucionales justos, por representantes elegidos adecuadamente y sujetas las

\begin{tabular}{|l|l|l|l|l|}
\hline Q Revista Dialectus & Ano 8 & n. 15 & Agosto-Dezembro 2019 & p. 72-87 \\
\hline
\end{tabular}


discusiones a mecanismos deliberativos apropiados. De todos modos nada debe impedir que los ciudadanos impugnen las decisiones que perciben como injustas y por ello Pettit defiende un modelo bidimensional de democracia: electoral y contestatario a la vez. ${ }^{9}$

\begin{abstract}
Pero la legitimidad del régimen no requiere que los ciudadanos acepten las decisiones presuntamente injustas en silencio, tratando a la legislatura y al gobierno como un soberano absoluto. Les permite impugnar las decisiones de manera activa, ejerciendo un derecho y un poder que se les otorga en virtud de la Constitución mixta. De hecho, exige que la disputa popular esté disponible de manera sistemática y potencialmente efectiva, ya que se necesita para ayudar a garantizar que la ciudadanía tenga una forma adecuada de control sobre el gobierno. La legitimidad del régimen excluye únicamente la resistencia extraconstitucional (PETTIT, 2016, p.33).
\end{abstract}

\title{
La interpretación de la voluntad general
}

La lectura de Pettit con respecto a la imposibilidad de contestación en Rousseau sostengo que está vinculada a un enfoque interpretativo sobre la voluntad general rousseauniana que denominaré "versión densa" (Diab, 2012, p.12). Esta asunción lo conduce a afirmar la negativa de Rousseau frente a la contestación. Quienes han asumido tal interpretación identifican a Rousseau o bien con un modelo democrático fuertemente participacionista (Affeldt, 1999) o bien con modelos despóticos (Berlin, 2004). Las consecuencias que Pettit extrae del modelo político de Rousseau parecen acercar su posición a esta última forma de comprender la voluntad general y sus implicancias. Se trata de una perspectiva relativamente estándar desde la cual se percibe la voluntad general como una totalidad sustantivamente homogénea, cuya existencia no sólo trasciende ontológicamente la mera suma de las voluntades individuales (voluntad de todos) sino que suprime valorativamente a la voluntad individual. Bajo las condiciones de la voluntad general las diferencias individuales deben quedar suprimidas. Según este modo de comprender la voluntad general, ésta representa un modelo comprehensivo de vida buena definido principalmente por la participación cívica la cual se identifica con la plena realización moral y política de la condición humana. La interpretación que hace Pettit de la voluntad soberana en Rousseau hace hincapié en la concepción heredada de Hobbes y Bodin en su carácter de

9 Este aspecto de su teoría ha sido desarrollado a lo largo de su obra: Pettit (1999), Pettit (1999a), Pettit (2006), Pettit (2012), Pettit (2014), entre otros.

\begin{tabular}{|l|c|c|c|c|}
\hline Qovista Dialectus & Ano 8 & n. 15 & Agosto-Dezembro 2019 & p. $72-87$ \\
\hline
\end{tabular}


indivisibilidad y homogeneidad y por ello parece asumir esta interpretación estándar de la voluntad general como una realidad opresora de la individualidad y de los intereses particulares.

Sin embargo es posible caracterizar la voluntad a partir de otros enfoques, desde los cuales entiendo que la comprensión sobre el lugar de la contestación varía. Tomaré como ejemplo el análisis que John Rawls realiza de la voluntad general (2009, p.245-287). Rawls fundamenta que la voluntad general en Rousseau no supone la negación de los intereses particulares de los ciudadanos, no se trata de una realidad ontológica que los trasciende. Rechaza una perspectiva orgánica de la voluntad general como se describía anteriormente. Su planteo parte del análisis del siguiente pasaje del Contrato:

Si el Estado o la ciudad es tan sólo una persona moral cuya vida consiste en la unión de sus miembros, y si el más importante de sus cuidados es el de su propia conservación, necesita una fuerza universal y compulsiva a fin de mover y disponer cada parte de la manera más conveniente para el todo. Así como la Naturaleza da a cada hombre un poder absoluto sobre todos sus miembros, el pacto social le da al cuerpo político un poder absoluto sobre todos los suyos, y es ese mismo poder el que, dirigido por una voluntad general, lleva, como ya he dicho, el nombre de soberanía.

Pero, además de la persona pública, tenemos que considerar las personas privadas que la componen, y cuya vida y libertad son naturalmente independientes de ella. Se trata, pues, de distinguir bien los derechos respectivos de los ciudadanos y del soberano, y los deberes que tienen que cumplir los primeros en calidad de súbditos con respecto al derecho natural del que deben gozar en calidad de hombres (CS, 2008, I, cap.4, p.73).

Rawls se detiene en el segundo párrafo del texto por la distinción que allí Rousseau realiza entre los derechos del individuo en tanto ciudadano, como miembro del cuerpo soberano y los derechos del individuo como persona particular, independientes del cuerpo político. ${ }^{10}$ A partir de allí Rawls interpreta que la voluntad general es la voluntad del individuo actuando y decidiendo en el ámbito público como ciudadano mientras que la voluntad individual representa los intereses particulares del mismo. Rawls sostiene que son los ciudadanos individuales los que tienen una voluntad general, a la cual identifica con la facultad deliberante y que permite orientar la acción hacia el bien común en ocasiones apropiadas. La voluntad general y la particular apuntan a intereses diversos pero no tienen una existencia separada, conviven en el ciudadano y representan puntos de vista distintos. Cuando se actúa en el espacio público

10 Trabajado también en Diab (2012).

\begin{tabular}{|c|c|c|c|c|}
\hline Revista Aldectus & Ano 8 & n. 15 & Agosto - Dezembro 2019 & p. $72-87$ \\
\hline
\end{tabular}


en virtud de los principios fundamentales que son iguales para todos, lo que se demanda al individuo es que tome la perspectiva de la voluntad general. El concepto de punto de vista remite a la noción de razón deliberativa, y como tal tiene cierta estructura, sólo admite la definición de cuestiones relativas a normas constitucionales o leyes básicas y sólo cierto tipo de razones pueden ser aceptadas en esa reflexión. Rawls sostiene: "De todo esto se desprende claramente, pues, que la perspectiva de Rousseau contiene una concepción de lo que yo he llamado razón pública” (Rawls, 2009, p.290).

Asumir el punto de vista de la voluntad general implica una ventaja fundamental para el individuo con respecto a sus condiciones en un estado pre social en el cual sus derechos fundamentales no están garantizados, implica garantizar el pacto por el cual los individuos se mantienen igualmente libres. Pero, tal como observa Rawls, el pasaje de una libertad natural a una libertad moral es favorable siempre que el precio no sea el sufrimiento por el abuso de la autoridad política. (Rawls, 2009, p. 302). El ciudadano bajo las condiciones del contrato no puede ser degradado a una condición similar de la cual el pacto lo libró. En los términos de Rousseau:

\footnotetext{
Tan sólo entonces, cuando la voz del deber sucede al impulso físico y el derecho, al apetito, el hombre que hasta entonces no había mirado más que a sí mismo, se ve obligado a actuar según otros principios y a consultar su razón antes de escuchar sus inclinaciones. Aunque en este estado se prive de diversas ventajas provenientes de la naturaleza, gana en cambio muy grandes: sus facultades se ejercitan y se desarrollan, sus ideas se amplían, sus sentimientos se ennoblecen, su alma entera se eleva a tal punto que, si los abusos de la nueva condición no lo degradaran a menudo por debajo de aquella de donde procede, debería bendecir sin cesar el instante que lo arrancó de ella para siempre y que, de un animal estúpido y limitado, hizo un ser inteligente y un hombre. (CS, 2008, I, cap.8, p.59-60).
}

Por lo tanto ingresar al cuerpo político, contratar para alcanzar un nuevo tipo de libertad, no puede significar obedecer cualquier ley que se prescriba (Rawls, 2009, p.303). Los ciudadanos pueden errar en sus juicios, pueden estar mal informados o manipulados teniendo como resultado leyes injustas y Rousseau advierte sobre la necesidad de reducir esas distorsiones (CS, 2008, II, cap.3, p.71-72). Sólo cabe obedecer aquellas "leyes fundamentales promulgadas de forma apropiada y conforme a la voluntad general (una forma de razón deliberativa)" (Rawls, 2009, p.303). Por lo tanto cuando no están dadas las condiciones de una deliberación justa bajo las cuales el ciudadano no tenga las garantías de libertad, es decir bajo las cuales se encuentre dominado, no tiene razón para obedecer. A partir de esta perspectiva de la voluntad

\begin{tabular}{|l|l|l|l|l|}
\hline Govista Dialectus & Ano 8 & n. 15 & Agosto-Dezembro 2019 & p. 72 - 87 \\
\hline
\end{tabular}


general es posible deducir que la contestación es perfectamente legítima como vía para la plena realización del contrato por el cual los individuos se encuentran libres de dominación.

El aspecto fundamental de la caracterización anterior que permite dar cuenta de la contestación es el énfasis en la distinción entre la voluntad general y la voluntad individual, entre lo universal y lo particular. Si bien es cierto que en Rousseau la voluntad general se defiende contra las divisiones y la opresión de las facciones, ella actúa sobre un trasfondo de pluralidad a la que aspira preservar"11, "alentando a los grupos e individuos a construir metas y objetivos comunes en la búsqueda de una sociedad orientada a maximizar la libertad y la igualdad." (Inston, 2010, p.107). Esta búsqueda de metas comunes con las cuales los individuos o grupos particulares se identifiquen, supone una construcción permanente en un proceso de "desnaturalización" de las tendencias particularistas y desarrollo de intereses comunes pero sin dejar de preservar la autonomía.

La preservación de su autonomía es imperativa para su comprensión de una voluntad general abierta a la reevaluación y el cambio. Al entrar en el contrato, los ciudadanos no sólo acuerdan seguir las leyes que autorizan, sino también criticarlas y potencialmente cambiarlas en la búsqueda continua de justicia: de ahí el énfasis de Rousseau en la dimensión de la voluntad en la voluntad general" (INSTON, 2010, p.110). ${ }^{12}$

La tensión entre las voluntades particulares que tienden hacia lo parcial y la voluntad general que tiende a la igualdad, necesita que los ciudadanos se encuentren siempre prevenidos a repensar y actualizar los lazos contractuales, "dado que nunca tenemos la certeza de que la voluntad general es realmente general” (Inston, 2010, p.131). Ningún cuerpo legal establecido puede ser equiparado de una vez y para siempre con la voluntad general, ni el gobierno ni los magistrados pueden pretender que el pacto soberano les atribuye una carta en blanco y esto necesita de una vigilancia perenne.

No basta que el pueblo reunido haya fijado una vez la constitución del Estado sancionando un cuerpo de leyes; no basta que haya establecido un gobierno perpetuo o que haya asegurado de una vez por todas la elección de magistrados. Además de las asambleas extraordinarias exigidas por casos imprevistos, es necesario que haya otras fijas y periódicas que no se puedan abolir ni prorrogar, de tal modo que en el día señalado el pueblo sea

11 Concuerdo con Inston quien sostiene que la noción de voluntad general en Rousseau ofrece una concepción de la universalidad más plural, contingente y abierta (2010, p.110).

12 La traducción es propia.

\begin{tabular}{|l|l|l|l|l|}
\hline Q Rovista Dialectus & Ano 8 & n. 15 & Agosto - Dezembro 2019 & p. 72-87 \\
\hline
\end{tabular}


legítimamente convocado por la ley, sin que se necesite para ello ninguna convocatoria formal (INSTON, 2010, p.131). ${ }^{13}$

Existen muchas disquisiciones y distinciones conceptuales necesarias para tratar adecuadamente el complejo enfoque teórico de Rousseau sin violentar sus principales aspiraciones. Seguramente en este trabajo muchas de ellas han sido pasadas por alto. En el caso de Pettit creemos que en el análisis del dilema rousseauniano le ocurre algo similar. Plantea el problema de la contestación principalmente vinculado a la soberanía mientras debería hacerlo desde la perspectiva del gobierno, de la administración. ${ }^{14}$ Para Rousseau no es posible cuestionar el pacto y la voluntad soberana emanada del mismo, y esto para Pettit representa una forma de dominación estatal (imperium). Sin embargo la preocupación de Rousseau no es otra que la que cualquier defensor de un Estado constitucionalmente bien formado, y el mismo Pettit, tienen. Se trata de que una vez establecido un orden social y político legítimamente fundado se cuente con las garantías para su conservación, para su estabilidad. El modelo de contestación de Pettit supone cuestionar las decisiones públicas pero siempre respetando el orden instituido. (Pettit, 2016, p.33) En el diseño institucional que propone la disputación nunca se puede transgredir las leyes establecidas, inclusive en el caso en que el proceso de disputación resulte en una respuesta desfavorable para el o los ciudadanos. El mecanismo de contestación de las leyes no dispone al ciudadano a renunciar al sistema a través de resistencia violenta o acciones subversivas, quien se halla dispuesto a disputar una decisión pública lo hace desde dentro del sistema. (Pettit, 2014, p.114-115) ¿No significa eso preservar incuestionado el poder soberano legítimamente establecido? Entiendo que sí. La contestación de las decisiones públicas es justificada en Rousseau tanto como en Pettit, así como en ninguno de ellos es posible justificar la disputación del pacto general sobre la base del cual tales decisiones se toman. Aun así, garantizar canales de contestación para cumplir con el imperativo republicano de la vigilancia perenne no basta para contar con una ciudadanía dispuesta a cuestionar activamente al poder público y menos de hacerlo en virtud de un bien

13 No entraré aquí en la discusión sobre el modelo asambleario de Rousseau y la desconfianza que despierta en Pettit.

14 Por supuesto que aquí no se está afirmando que el filósofo no reconoce tal distinción, sin embargo el énfasis puesto en la imposibilidad de cuestionar el poder soberano conduce a confusión en el planteo del problema.

\begin{tabular}{|c|c|c|c|}
\hline Rovista Dialectus & Ano 8 & n. 15 & Agosto - Dezembro 2019 \\
\hline
\end{tabular}


común. En Republicanismo Pettit reconoce que las instituciones republicanas no pueden funcionar por sí solas para proteger al ciudadano de la dominación. Es necesario el compromiso de los individuos con dicho valor y todo lo que conlleva. Las instituciones sin disposiciones cívicas “[son] resortes muertos, mecánicos, y sólo ganarán vida y cobrarán impulso si se hacen sitio en los hábitos de los corazones de las gentes." (Pettit, 1999, p.313) Pero no es por un acto de magia que estos hábitos aparecen. Todo modelo político republicano que prevea un diseño institucional para garantizar la libertad como no dominación debería asumirlo y en ello Rousseau tiene mucho para decirle a Pettit.

\section{Referencias:}

AFFELDT, S. The force of freedom: Rousseau on forcing to be free. En: Political Theory, Vol. 27, no.3, junio 1999.

BERGES, Sandrine. Interview with Professor Philip Pettit. En: Étique et économique/Ehics and Economics, 3, (2), 2006.

BERLIN, Isaiah. Rousseau. En: BERLIN, Isaiah. La traición de la libertad. México DF: FCE, 2004, p.49-75.

BRAITHWAITE, John \& PETTIT, Philip. No sólo su merecido. Por una justicia penal que vaya más allá del castigo. Buenos Aires: Siglo Veintiuno Editores, 2015.

DE FRANCISCO, Andrés. Ciudadanía y democracia. Un enfoque republicano. Madrid: Los libros de la Catarata, 2007.

DIAB, Fernanda. Rousseau: el fundamento igualitarista y la noción de libertad. En: Actio, No 14, diciembre 2012, p. 11-20.

INSTON, Kevin. Rousseau and Radical Democracy. NY, London: Continuum books, 2010.

PETTIT, Philip. Republicanismo. Una teoría sobre la libertad y el gobierno. Barcelona: Paidós, 1999.

Republican freedom and contestatory democratization. En: SHAPIRO, I. and HACKER-CORDON, C. (Eds.). Democracy's Value. Cambridge: Cambridge University Press, $1999^{\mathrm{a}}$.

- Una teoría de la libertad. De la psicología a la acción política. Madrid: Editorial Losada, 2006.

\begin{tabular}{|l|l|l|l|l|}
\hline Q Povista Dialectus & Ano 8 & n. 15 & Agosto-Dezembro 2019 & p. 72 - 87 \\
\hline
\end{tabular}


Democracy, Cambridge: Cambridge University Press, 2012.

----------. Two Republican Traditions. En: NIEDERBERGER, A. and SCHINK, P. (Ed.). Republican Democracy: Liberty, Law and Politics. Edinburgh: Edinburgh University Press, 2013.

-----------. Just Freedom. A moral compass for a complex world. NY: Norton \& Company, 2014

Rousseau's dilemma. En LIFSCHITZ, A. (Ed.). Engaging with Rousseau: reception and Interpretation from the Eighteengh Century to the Present. Cambridge: Cambridge University Press, 2016, p.168-188.

PINZANI, Alessandro. Republicanismo(s), democracia, poder. En: Veritas, V.52, No 1, marzo 2007, p. 5-15.

RAWLS, John. Lecciones sobre Rousseau. En: RAWLS, John. Lecciones sobre la historia de la filosofía política. Madrid: Paidós, 2009, p. 245-287.

RIVERA GARCÍA, Antonio. La constitución mixta, un concepto político premoderno. En: Historia y Política, núm. 26, julio-diciembre 2011, págs. 171-197.

ROUSSEAU, Jean-Jacques. El contrato social. Discursos. Buenos Aires: Editorial Losada, 2008.

WIRSZUBSKI, C. Libertas as a Political Idea at Rome. Oxfrod: Oxford University Press, 1968.

\begin{tabular}{|l|l|l|l|l|}
\hline Q Povista Dialectus & Ano 8 & n. 15 & Agosto - Dezembro 2019 & p. 72-87 \\
\hline
\end{tabular}

